\section{Компьютеризированная система выбора машин для рубок промежуточного пользования ${ }^{1}$}

\author{
В. С. Сюнёв ${ }^{2}$ \\ Петрозаводский государственный университет
}

\begin{abstract}
АННОТАЦИЯ
Рассмотрен подход к обоснованию выбора машин для рубок промежуточного пользования (несплошных рубок леса) на основе создания и применения компьютеризированной системы принятия решений, позволяющей сбалансированно учитывать как производственные, так и экологические показатели функционирования машин.
\end{abstract}

Ключевые слова: промежуточное пользование, лесозаготовительные машины, принятие решения, экологический фактор.

\section{SUMMARY}

The optimal choice of forest harvesting machines for thinning should take into consideration many aspects: productivity, ecological friendliness to the environment to inflict less damage on remaining trees and forest soil, fulfillment of planned thinning regime. All the requirements are taken into consideration in computerized decision making system. The system is based on GIS and has four main blocks: model of forest site (describing stand structure, soil, land relief, climate); forest machine data base; harvesting process simulation model; results of calculation and optimal design block.

Keywords: thinning, harvesting machines, decision making, ecological factor.

\section{ВВЕДЕНИЕ}

Одним из перспективных направлений лесной политики является развитие рубок промежуточного пользования. После спада, постигшего лесозаготовительные производства в 1993-1997 годах, этот вопрос вновь становится актуальным в связи с тем, что, вопервых, в ряде регионов (особенно приближенных к внешним рынкам) растет процент освоения расчетной лесосеки по главному пользованию и вновь в перспективе встанет вопрос о необходимости получения древесины от несплошных рубок, а, во-вторых, значительная часть лесного фонда находится в недоступных и труднодоступных районах и для получения дополнительной древесины на уже освоенных территориях перспективным оказывается внедрение несплошных форм хозяйствования.

\footnotetext{
1 Работа выполнена при финансовой поддержке гранта Министерства образования РФ Т02-11.1-279

${ }^{2}$ Автор - профессор кафедры тяговых машин

(C) В. С. Сюнёв, 2003
}

Как и прежде, развитие несплошных форм рубок сдерживается техническими возможностями. Решение данной проблемы предполагает как экстенсивный, так и интенсивный пути.

Экстенсивный путь - наращивание номенклатуры и числа машин и оборудования - предполагает оживление деятельности лесного машиностроения, в том числе конверсионного, увеличение импорта, создание новых машин, подобных лучшим зарубежным аналогам. На первом этапе работ в этом направлении целесообразно использовать положительный опыт разработки конструкций специальных лесных машин по модульному принципу на базе колесных сельскохозяйственных тракторов. Создание таких машин требует научного обоснования их основных параметров в соответствии с будущими условиями эксплуатации.

Решение вопроса машинизации за счет простого увеличения числа машин и оборудования является недостаточным шагом. Интенсивный путь предполагает организацию более эффективного использования машин. При этом требуется удовлетворение комплекса требований по производительности, металлоемкости, выполнению намеченной программы рубок. Особое значение должно уделяться экологическому аспекту проведения рубок ухода.

На современном научном уровне решение проблемы машинизации рубок ухода и экстенсивным и интенсивным путями предполагает разработку нового концептуального подхода, неразрывно связанного с вопросами информатизации и компьютеризации лесной отрасли. Суть данного подхода заключается в создании компьютерной системы поддержки принятия решений по выбору и обоснованию машин для проведения рубок в конкретных условиях. Такая система позволяет при учете многообразия природнопроизводственных факторов и альтернативном наборе машин осуществлять оптимальный подбор машин из числа существующих. При отсутствии необходимого варианта выбора система позволяет проводить обоснование основных параметров вновь проектируемых машин и оборудования.

\section{ЗАДАЧИ ИССЛЕДОВАНИЙ}

Исходя из описанной проблемы нами в начале 1998 года были сформулированы следующие задачи исследований, которые необходимо было выполнить в рамках программы по созданию компьютеризированной системы выбора машин для несплошных рубок леса:

- Разработать компьютерные базы данных по имеющимся машинам для рассматриваемых видов рубок и установить зависимости между их основными параметрами. Решение этой задачи усложнялось тем обстоятельством, что большинство подобных машин производилось на западе, в основном в Финляндии и Швеции. Это предполагало организацию контактов с зарубежными партнерами по сбору и анализу информа- 
ции, генерацию новых научных проектов, охватывающих и эту проблематику.

- Создать базы данных по природнопроизводственным условиям на основе использования ГИС-технологий и провести компьютерное генерирование типовых модельных лесосек. Эта задача осложнялась выбором конкретного объекта исследований. Поскольку отработка методики создания баз данных даже в рамках отдельной республики и района оказалась бы весьма трудоемкой, мы ограничились исследованиями по конкретной территории лесничества Петрозаводского государственного университета (Пряжинский район Республики Карелия).

- Разработать компьютерные модели для исследования воздействия ходовых систем на лесные почвы, отражающие специфику лесных почв (наличие корней и камней).

- Провести комплекс экспериментальных исследований по воздействию машин на лесную среду (почвы, оставляемый древостой), оценить адекватность разработанных компьютерных моделей.

- Разработать имитационную компьютерную модель технологического процесса несплошных рубок с применением машинного комплекса (харвестер и форвардер).

- Оценить достоверность результатов имитационного моделирования натурным экспериментом, что потребовало создание методики эксперимента и организации и проведения реальных рубок на нескольких пробных площадях.

- Обосновать показатели для оценки эффективности функционирования машин на несплошных рубках и разработать методику их расчета. В качестве одного из основных показателей изначально предлагалось принять экологическую совместимость машин с природной средой. Здесь в первую очередь следовало учитывать повреждаемость оставляемого древостоя и лесных почв.

Структура запланированных исследований в соответствии с описанными задачами представлена на рис. 1.

\section{ФОРМИРОВАНИЕ ИССЛЕДОВАТЕЛЬСКОГО КОЛЛЕКТИВА И ОРГАНИЗАЦИЯ РАБОТЫ}

Основу исследовательского коллектива составили докторант и два соискателя ученой степени кандидата технических наук кафедры тяговых машин ПетрГУ при научном консультировании доктора технических наук, профессора Ю. Ю. Герасимова. Успешному решению поставленных задач способствовало их включение в программы ряда научноисследовательских проектов. Создание баз данных по лесозаготовительной технике проводилось нами на основе анкетирования фирм-производителей, поддержанного финляндской исследовательской группой
FEG (г. Йоэнсуу) и Государственным научным центром ЛПК при Минэкономики Российской Федерации. Сбор данных по природно-производственным условиям исследуемой территории и организация экспериментальных рубок леса оказались наиболее трудоемкими задачами исследований. Эти работы выполнялись в рамках двух международных проектов «Taiga-Model Forest» (Россия-Финляндия, 1997-2000 гг.), «Tempus Tacis T_JEP 10347-97 Development of the Environmental and Economics Studies» (РоссияФинляндия-Швеция, 1997-2000 гг.) и отечественного гранта «Разработка научных основ обоснования оптимального технологического процесса освоения лесных массивов при несплошных рубках».

\section{ПОДХОД К РЕШЕНИЮ ПОСТАВЛЕННОЙ ПРОБЛЕМЫ}

Подход к решению поставленной проблемы основывался на построении блочно-иерархической трехуровневой человеко-машинной (компьютеризированной) системы принятия решений.

Нижний уровень - оперативное планирование - представляет собой систему принятия решений по оценке эффективности работы машин в условиях конкретного хозяйства (лесхоз, лесопромышленное предприятие). Средний уровень - стратегическое планирование - позволяет проводить оптимальный выбор машин, имеющихся на рынке лесозаготовительной техники, для конкретных условий лесной среды в масштабах задач, решаемых региональными государственными лесохозяйственными органами и крупными лесопромышленными объединениями. Верхний уровень - проектный - позволяет конструкторуразработчику новой техники научно обосновывать основные параметры проектируемых машин в соответствии с будущими условиями эксплуатации.

На каждом уровне система состоит из определенного набора блоков, детальность разработки которых определяется масштабом решаемых задач:

- блоки средств информационной поддержки (компьютерные базы данных по имеющейся лесной технике и модельным лесосекам, увязанные с географическими информационными системами по лесным территориям);

- блок моделирования воздействия ходовых систем машин на лесные почвы;

- блок имитационных моделей, описывающих технологический процесс рубок ухода с расчетом частных показателей качества эффективности функционирования и полипоказателей.

Система производит расчет показателей, характеризующих работу машин, на основе анализа которых человеком-пользователем принимается решение соответствующего поставленным задачам уровня.

В качестве частных показателей эффективности функционирования машин предложено использовать: 
- показатель повреждаемости крон и стволовой части деревьев $\mathbf{W}_{\text {повр }}^{\mathbf{c}}$;

- $\quad$ показатель повреждаемости корневых систем и почвы $\mathbf{W}^{\mathbf{k}}$ повр;

- показатель пространственной доступности деревьев в рубку $\mathbf{W}_{\text {дост }}$;
- показатель производительности харвестера $\mathbf{W}_{\text {произв; }}^{\mathbf{X}}$

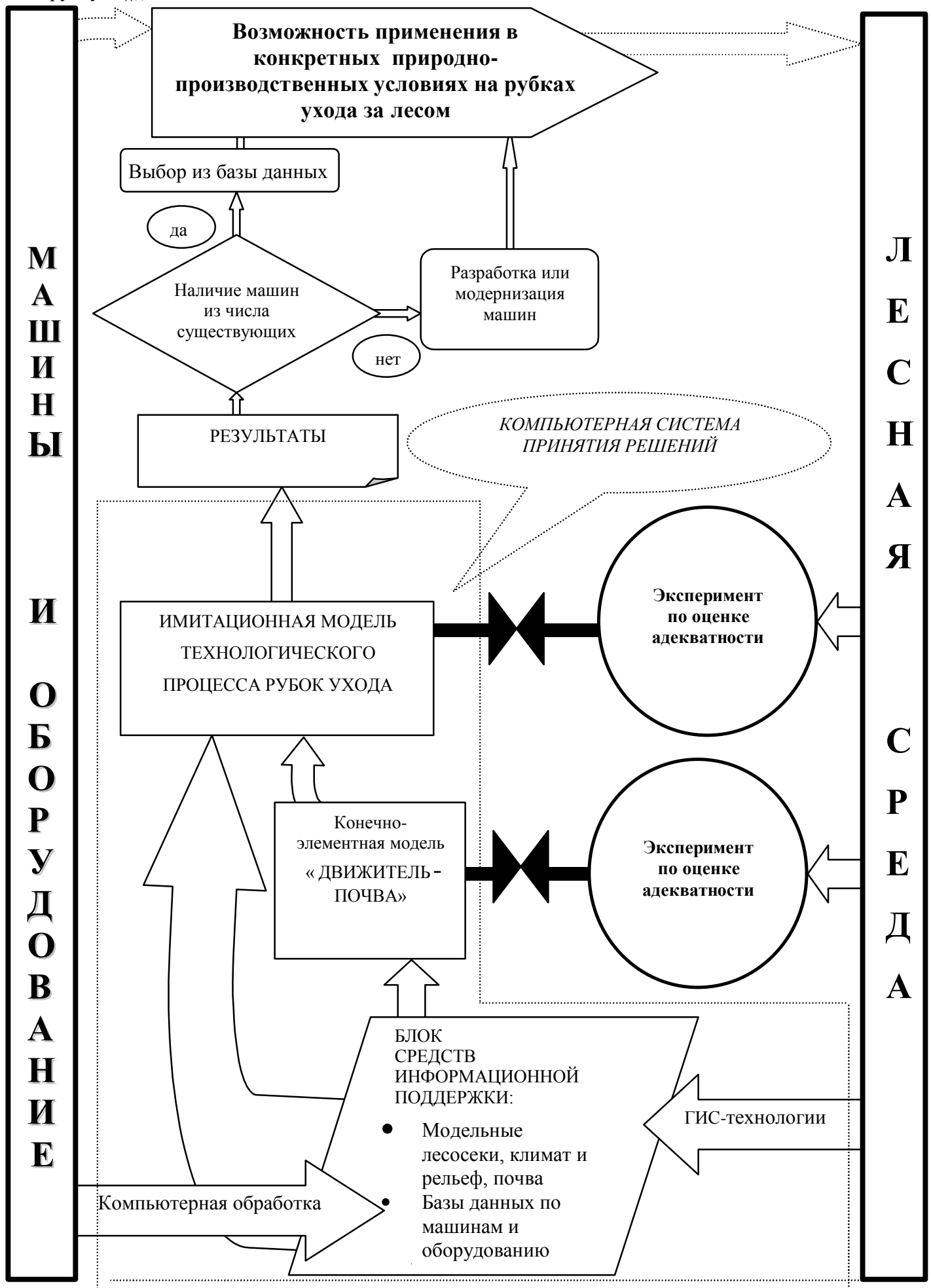

Рис. 1. Структура исследований по разработке компьютеризированной системы принятия решений 
- показатель производительности форвардера $\mathbf{W}_{\text {произв; }}^{\Phi}$

- показатель, характеризующий выполнение намеченного плана рубок (показатель качества рубки), $\mathbf{W}_{\text {кач; }}$;

- $\quad$ показатель, характеризующий металлоемкость харвестера, $\mathbf{W}^{\mathbf{X}}$ мет

- $\quad$ показатель, характеризующий металлоемкость форвардера, $\mathbf{W}_{\text {мет; }}^{\boldsymbol{\Phi}}$

- $\quad$ показатель, характеризующий степень согласованности машин в системе (харвестера и форвардера), $\mathbf{W}_{\text {сист. }}$

Определяющим критерием в принятии решения является полипоказатель качества Wij(u,v). Для повышения достоверности информации результирующий полипоказатель определяется тремя различными методами: методом равномерной оптимальности Критерий 1, методом свертывания (Гермейера) Критерий 2 и методом справедливого компромисса Критерий 3.

Принятие решения (для соответствующего иерархического уровня) проводится на основе анализа величин полипоказателей качества и частных показателей с использованием теории игр и статистических решений. Наилучшая альтернатива характеризуется наиболее удачным сочетанием всех показателей.

Уровень решаемых задач определяет характер связей между блоками и степень их задействованности в процессе принятия решения. На уровне оперативного планирования в лесхозе или леспромхозе в блоке информационной поддержки на основе использования ГИС данной территории создаются модельные лесосеки. Поскольку состав используемых машин ограничен и определен заранее, то электронные базы данных по машинам и оборудованию включены в работу частично. Минуя блок моделирования воздействия ходовых систем машин на лесные почвы, информация поступает в блок имитационного моделирования, описывающий технологический процесс рубок ухода. Здесь в конце моделирования рассчитываются показатели эффективности работы машин. На основе анализа величины показателей лицом, принимающим решение, делается заключение о целесообразности применения имеющихся машин в конкретных условиях, уточняются и корректируются планы проведения работ для обеспечения наибольшей эффективности имеющейся техники.

На уровне стратегического планирования компьютеризированная система принятия решений дополнительно к предыдущим предполагает включение в работу электронных баз данных по рынку техники для машинизации рубок. В результате выполнения описанной процедуры принятия решений делается заключение об оптимальном подборе машин для конкретных природно-производственных условий или даются рекомендации по распределению приобретен- ных машин по конкретным предприятиям с целью обеспечения максимальной эффективности их использования.

На верхнем уровне предлагается использование всех имеющихся блоков системы, в том числе блока моделирования воздействия ходовых систем машин на лесные почвы. Использование данного блока позволяет вводить в блок имитационного моделирования более точную информацию, проводить сравнение различных машин по степени отрицательного воздействия на лесную почву и вычислять показатели оценки воздействия машин на почвы. Оценка воздействия ходовых систем машин на лесные почвы производится по величинам удельного давления на почву в контакте с движителем q, напряжениям в почвенном слое $\sigma_{h}$, глубине колеи h. Возможно применение и производных от данных величин показателей. Наличие дополнительных показателей способствует более точному принятию проектного решения. Таким решением может быть выбор машин и оборудования из имеющейся номенклатуры, проектирование новых машин с обоснованием их основных параметров.

\section{РАЗРАБОТКА СРЕДСТВ \\ ИНФОРМАЦИОННОГО ОБЕСПЕЧЕНИЯ КОМПЬЮТЕРИЗИРОВАННОЙ СИСТЕМЫ ПРИНЯТИЯ РЕШЕНИЙ}

Система информационного обеспечения включает два независимых блока:

- компьютерную базу данных по существующим лесным машинам и оборудованию (манипуляторы, рабочие органы);

- $\quad$ компьютерную базу данных по модельным лесосекам.

В компьютерную базу по машинам и оборудованию вошли данные о более чем четырехстах единицах зарубежных и отечественных машин и оборудования, полученные при анкетировании более 100 предприятий-изготовителей. Программный продукт, взятый за основу при создании базы данных, - Microsoft Excel 5.0 для Microsoft Windows. Методический подход к построению баз данных и их структура описаны нами в работах $[1,2,3]$.

В качестве исходных данных для построения модели лесосеки служат характеристики деревьев, почвенногрунтовых условий, климата и рельефа, содержащиеся в банках данных, полученных с использованием ГИС-технологий (лесоустройство, климат, топография и почвы и т. д.).

База данных по модельным лесосекам должна содержать сведения о природно-производственных условиях. Модельные лесосеки получены путем генерирования на компьютере характеристик древостоя и местности. Ввод исходных характеристик, полученных в ходе экспедиционных работ в учебно- 
производственном лесничестве университета, и вывод результатов моделирования проводятся в среде пакета программ MapInfo для Microsoft Windows [4].

\section{МОДЕЛИРОВАНИЕ ВОЗДЕЙСТВИЯ ХОДОВЫХ СИСТЕМ МАШИН НА ЛЕСНЫЕ ПОЧВЫ}

Исследование процессов взаимодействия ходовых систем с почвой было предложено проводить на основе применения метода конечных элементов (МКЭ). Применение данного метода позволяет наиболее точно описать процесс взаимодействия движителей и почвы, определить деформации и напряжения в любой точке любого почвенного слоя, использовать для описания почвы модель упруго-пластической среды, оценить уплотняемость почвы, исследовать последствия многократных проходов машин по одному следу [5]. При этом в отличие от аналитических методов форма линии контакта ходового элемента (например, эластичной пневматической шины) с почвой не оговаривается предварительно, а получается в результате моделирования в соответствии с рассматриваемыми характеристиками почвы и ходового элемента. Метод позволяет проводить сравнительную оценку показателей, характеризующих последствия движения разных типов машин (колесных и гусеничных) по одной и той же почве в одинаковых условиях, и давать заключение о предпочтительности их применения. Важным преимуществом метода, особенно при рассмотрении экологически ориентированных задач, является его наглядность, обеспечиваемая визуализацией исследуемых процессов на экране монитора компьютера.

На основе использования ГИС-технологий рассмотрена возможность создания электронной почвенной карты местности с координатно-привязанными базами данных по характеристикам почв.

Определение входных параметров модели прочности почвы осуществляется по результатам прочностных испытаний почвенных образцов (строится линия поверхности предельных напряжений в меридиональном плане, по которой определяются инварианты напряжений для модели Друккера - Прагера).

В предлагаемом подходе к моделированию почвы возможен учет армирующего влияния корневых систем растений и наличия камней.

Пневматическое колесо моделируется в виде трех концентрических окружностей с разными упругими свойствами: протекторная часть, каркас, стальной обод. Гусеничный движитель моделируется в виде упругой многозвенной балки с жесткими катками на ней.

Предлагаемая конечно-элементная модель была формализована в пакете прикладных программ ANSYS, что позволило рассчитывать не только значение исследуемых параметров, характеризующих воздействие машин на почву, но и визуализировать исследуемые процессы на экране монитора (рис. 2).

\section{ИМИТАЦИОННАЯ МОДЕЛЬ ТЕХНОЛОГИЧЕСКОГО ПРОЦЕССА НЕСПЛОШНЫХ РУБОК}

Основным звеном компьютеризированной системы принятия решений является имитационная модель функционирования машинного комплекса на заготовке леса. Структура обеспечения функционирования имитационной модели показана на рис. 3 .

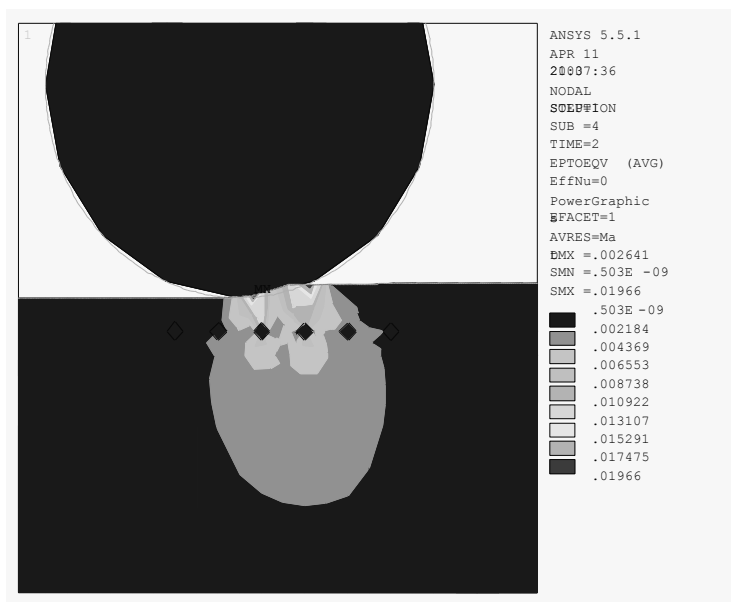

Рис. 2. Картина напряжений в почве при наличии корней

Входные элементы природного вектора $\mathbf{v}$ формируются в блоке информационной поддержки и представлены следующими модулями:

А. "Программа рубок" - число и степень изреживаний древостоя при рубках ухода.

В. "Горизонтальная структура" и "Вертикальная структура" - распределение деревьев по площади и их размеры.

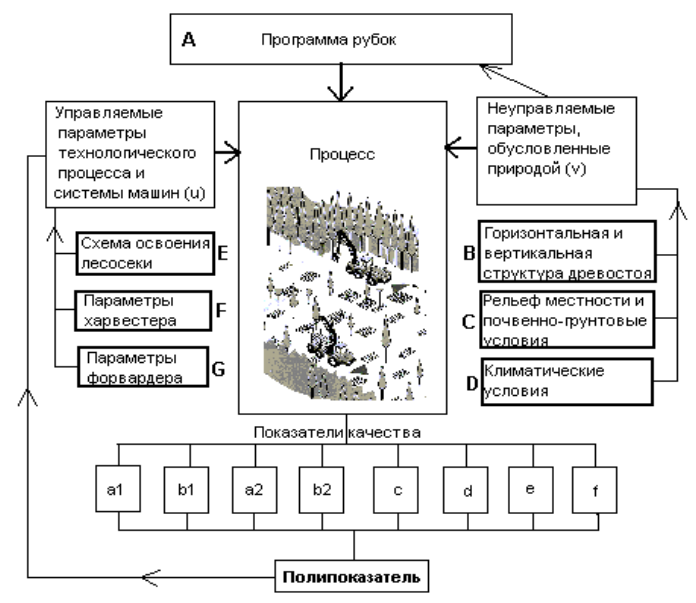

Рис. 3. Структурная схема имитационной модели

С. "Местность" - параметры, характеризующие рельеф и почвенно-грунтовые условия. 
D. "Климат" - параметры, характеризующие климатические условия эксплуатации.

Элементы вектора субъекта принятия решения $\mathbf{u}$ представлены модулями, описывающими размеры и технологический план освоения лесосеки, основные параметры машин и оборудования для ее освоения.

E. "Схема освоения лесосеки" - размер делянки, планировка волоков и их размеры, процент выборки.

F. "Параметры лесозаготовительной машины" - конструктивные параметры валочно-пакетирующей машины или харвестера, включая характеристики манипулятора, ЗСУ или харвестерной головки.

G. "Параметры трелевочной машины" - конструктивные параметры скиддера или форвардера и применяемого технологического оборудования.

Модули $\mathbf{F}$ и $\mathbf{G}$ также формируются в блоке системы поддержки.

Центральный модуль "Процесс" объединяет и связывает всю поступающую информацию и описывает технологический процесс рубки.

Показатели качества рассчитываются в следующих модулях:

a1 - "Производительность лесозаготовительной машины"; b1 - "Металлоемкость лесозаготовительной машины"; $\mathbf{2} 2$ - "Производительность трелевочной машины"; b2 - "Металлоемкость трелевочной машины"; с - "Доступность деревьев в рубку"; d - "Качество рубки"; е - "Повреждаемость крон деревьев, стволов, корней и почв"; $\mathbf{f}$ - "Согласованность машин в системе".

Имитационная модель формализована на алгоритмическом языке MapBasic (в среде пакетов, поддерживающих ГИС) в виде четырех взаимоувязанных программ:

- моделирование движения лесозаготовительной машины с выбором точек стоянки, учетом рельефа и грунтовых условий, оценка доступности намеченных к валке деревьев, моделирование валки деревьев, комплексная оценка наносимых повреждений с учетом сезона работ, оценка металлоемкости, расчет производительности и времени);

- моделирование процессов обрезки сучьев, раскряжевки и пакетирования (если они предусмотрены технологическим процессом лесозаготовок) с учетом сезона работы и характеристик обрабатываемых деревьев;

- $\quad$ моделирование работы трелевочной машины;

- расчет частных критериев эффективности и полипоказателей.

\section{ЭКСПЕРИМЕНТАЛЬНАЯ ПРОВЕРКА АДЕКВАТНОСТИ РАЗРАБОТАННЫХ МОДЕЛЕЙ}

Целями экспериментов являлись проверка адекватности разработанной имитационной модели технологического процесса рубок и проверка адекватности конечно-элементной модели взаимодействия движителя с почвой.

В первом случае объектами исследований явились лесные участки учебно-опытного лесничества ПетрГУ (Пряжинский район, Республика Карелия) и лесные участки в провинции Северная Карелия (Финляндия). Рубки проводились в сосновых 60-летних древостоях, смешанных (ель-сосна) древостоях 60-летнего возраста и в еловых с примесью березы древостоях 40 и 60 лет на шести опытных участках, освоенных по различным технологическим схемам.

Система машин, используемая для экспериментальной рубки, представляла колесный харвестер $(4 \mathrm{x} 4)$ Timberjack-870, оснащенный харвестерной головкой TJ 746B, и колесный форвардер (8x8) Timberjack810В. Определение объема заготавливаемой древесины (в том числе отдельно по технологическим коридорам) проводилось с использованием штатного микрокомпьютерного устройства Timberjack 3000, которым оснащаются все производимые этой фирмой харвестеры. Учет производительности работы форвардера осуществлялся оператором машины и нормировщиком на погрузочном пункте. Данные по реальной производительности машин сравниваются с полученными при расчете на компьютере в ходе имитационного моделирования.

Для оценки качества выполнения программы рубок, доступности деревьев, повреждаемости почвы и оставленного на доращивание древостоя проводилась инвентаризация лесного участка до и после рубки. Инвентаризация основывается на методе исследования пробных площадей, размещаемых на сети мерных линий. Методика исследования подробно изложена нами в работе [6].

Сбор данных производился с использованием полевых карточек с последующей компьютерной обработкой результатов в электронных таблицах Excel.

По данным, полученным после обработки натурного эксперимента, проводился расчет показателей качества выполнения программы рубок, доступности и повреждаемости. После чего величины показателей сравнивались с результатами, рассчитанными при моделировании тех же природных условий, технологии и машин в компьютерном эксперименте.

Разница в величинах показателей, полученных на основе обработки натурного и компьютерного экспериментов, составила 5,5-11\%, что подтверждает возможность применения разработанных имитационных моделей в предлагаемой компьютеризированной системе принятия решений. 
Во втором случае в качестве объекта исследований были приняты наиболее распространенные трелевочные машины: колесный форвардер Timberjack-1010 финского производства и отечественные трактора ТДТ-55А с серийной (440 мм) и уширенной асимметричной (550 мм) гусеницами. В ходе этого блока экспериментальных исследований на специально организованных трассах производился замер глубины оставляемой колеи, плотности почвы на поверхности и на глубине 15-20 см, определялась её твердость (сопротивление пенетрации) до и после трех-, шести-, девятикратных проходов машин. По результатам дальнейшей обработки взятых с колеи и контроля почвенных образцов определялась пористость почв. Поскольку все исследуемые параметры существенно влияют на способность развития питающих корней деревьев в почвенном слое, то они являются важнейшими характеристиками для оценки экологической совместимости движителей машин с почвой. Для оценки адекватности конечно-элементной модели, описывающей взаимодействие движителей с почвой, нами были выбраны две величины: глубина колеи и изменение твердости почвы [7]. Сравнение экспериментальных данных с результатами моделирования подтвердило адекватность предложенных конечноэлементных моделей: разница по глубине образуемой колеи не превысила $8 \%$, разница в увеличении твердости почвы в колее составила 6-12\%.

Таким образом, проведенные эксперименты подтвердили адекватность предложенных моделей и возможности их использования в компьютеризированной системе принятия решений.

\section{ПРИМЕНЕНИЕ РАЗРАБОТАННОЙ КОМПЬЮТЕРИЗИРОВАННОЙ СИСТЕМЫ ПРИНЯТИЯ РЕШЕНИЙ}

Возможности использования предложенной системы принятия решений были продемонстрированы на примерах решения задач регионального подразделения органов лесного хозяйства и лесопромышленной компании.

Основные результаты работы внедрены в Карельском НИИ лесной промышленности при создании системы машин для рубок ухода, АХК «Кареллеспром», Государственном комитете по лесу Республики Карелия, в Государственном научном центре ЛПК при Минэкономики РФ, на ОАО «Онежский тракторный завод», в учебном процессе кафедры тяговых машин Петрозаводского государственного университета.
Основные положения и результаты работы были представлены на международных и региональных конференциях и практических семинарах, демонстрировались на Всероссийской выставке «Российский лес-99» в г. Вологда.

\section{СПИСОК ЛИТЕРАТУРЫ}

1. Сюнёв В. С., Герасимов Ю. Ю., Костюкевич В. М. Компьютерная информационная система “ХАРВЕСТЕРЫ" // Труды лесоинженерного факультета ПетрГУ. Вып. 1. Петрозаводск, 1996. C. 90-96.

2. Сюнёв В. С., Герасимов Ю. Ю., Костюкевич В. М. Компьютерные информационные системы по лесозаготовительной технике // Региональные проблемы развития лесного комплекса: Тезисы докладов республиканской научно-практической конференции / КарНИИЛП. Петрозаводск, 1998. C. $15-16$.

3. Сюнёв В. С., Герасимов Ю. Ю., Костюкевич В. М. Компьютерная информационная система "ФОРВАРДЕРЫ" // Труды лесоинженерного факультета ПетрГУ. Вып.2. Петрозаводск, 1999. C. 161-167.

4. Герасимов Ю. Ю., Сюнёв В. С. Моделирование, экологическая оптимизация и экспериментальные исследования техпроцессов и машин для рубок ухода на основе ГИС-технологий // Вестник Центрально-Черноземного регионального отделения наук о лесе РАЕН. Вып. 2. Воронеж, 1999. C. $115-118$.

5. Сюнёв В. С. Моделирование лесной почвы методом конечных элементов. Петрозаводский гос. ун-т. Петрозаводск, 2000. 19 с. Деп. в ВИНИТИ 06.06.2000, № 1617-В00.

6. Герасимов Ю. Ю., Кильпеляйнен С. А., Сюнёв В. С. Об экспериментальной оценке адекватности применения имитационного моделирования при исследовании рубок ухода // Труды лесоинженерного факультета ПетрГУ. Вып. 3. Петрозаводск, 2001. С. 19-23.

7. Сюнёв В. С., Давыдков Г. А. Воздействие машин на лесные почвы // Труды лесоинженерного факультета ПетрГУ. Вып. 3. Петрозаводск, 2001. C. 88-91. 